\title{
Queering Pride: Walking Towards a Queer Future in Ireland
}

\author{
Georgina Perryman
}

\section{Maynooth University, Dublin Ireland}

\begin{abstract}
The Queer History Walking Tour is an annually recurring event during Dublin's official Pride festivities. Created and led by the 'Godfather of Gay,' Tonie Walsh, the walks seek to extend stories from the Irish Queer Archive (IQA) into the everyday fabric of the city, contributing to a processual queering of Irish heteronormative histories. As an activist form of public pedagogy, the walking tour encourages a relational understanding of queer cultural heritage through mobile, embodied, and emotional interactions. This paper argues that the walking tour works as an anarchive that contributes to a growing, intersectional understanding of LGBTQ+ experiences and queer futures, facilitated by peripatetic practices. In response to pervasive cis-male homonormativity at Pride, Dr Mary McAuliffe, a queer feminist woman, is the latest tour guide who includes historical stories of lesbian women, trans people, and gay men. Through engaging with this diversity of historical experiences, guides signal and support anti-capitalist events organised to critique the corporatisation of Pride and current attitudes towards LGBTQ+ people in Ireland. Trans Pride and Alternative Pride highlight the ongoing physical and structural violence done to LGBTQ+ people through giving voice to intersectional experiences. They connect LGBTQ+ struggles across different timespaces through engaging with Pride as a protest and marching to significant historical sites on meaningful days in LGBTQ+ history. Walking together to significant places, telling stories, and educating one another at these events works to queer Pride by challenging capitalism and its norms, revealing a trajectory that invites us to imagine and participate in an intersectional future of being queer in Ireland.
\end{abstract}

\section{Keywords}

Guided tour; queer; storytelling; heritage; solidarity 
'[I]t's like a mini pride parade and we're wandering around Dublin, and there's no alcohol involved, and we're just sharing all these great stories. You're prompting me to actually recount some of my own personal stories to my friend!'

- Tonie Walsh (relaying an anecdote), personal communication, 2017

\section{Introduction}

Dublin Pride does not consist of one parade, but two. Every year, Dublin Pride includes a 'mini parade:' a free Queer History Walking Tour created and led by Tonie Walsh. As a founder of the Irish Queer Archive (IQA), co-founder of the Gay Community News (GCN) and long-time gay rights activist, Walsh is well known within the LGBTQ+ community in Ireland as the 'Godfather of Gay' (Mullally, 2018). The tour is highly popular and can draw up to 150 attendees, and sometimes includes collaborations with other historians with their own stories to tell. ${ }^{\mathrm{i}}$ The tour includes pausing alongside places of key significance in queer Irish history, be it a historical place that no longer materially exists, or one that has remained unchanged. This paper will draw on Walsh's walking tour to illustrate how walking tours generate a relational understanding of queer cultural heritage through mobile, embodied and emotional interactions with places and other queer people. I argue that, despite at first being singularly led by Tonie Walsh, the Queer History Walking Tour engages with a peripatetic processual queering of place; this queering contributes to a growing, intersectional understanding of LGBTQ+ experiences in Ireland, as invoked through the anarchive.

I start with locating myself and the context of the walking tour, after which I provide the context for the significance of this walking tour in Ireland today. Following a general discussion about walking tours as a relational activist public pedagogy, I describe how the queer walk through Dublin mobilises personal stories to extend the more intangible aspects of LGBTQ+ cultural heritage into the everyday fabric of the city. Drawing on an updated version of the tour that moves beyond Walsh's own white cis-male gay experiences, I discuss how the tour works to queer history and creates intergenerational solidarity amongst participants through walking. Finally, I connect the walking tour to contemporary divisions around Pride marches and related events, including Trans Pride, to consider LGBTQ+ people's immediate situation and signal an intersectional future of queer walking in Ireland.

\section{A Queer Experience}

The summer of 2017 was my first in Dublin and at Pride. As a quietly queer, white, demigirl 'blow-in 'ii from the UK, I did not feel ready for the large party that was Pride, but still wanted to participate to help me understand the histories of being queer in Ireland. Tonie Walsh's Queer History Walking Tour seemed like a good introduction, which he describes as: "an informative little exercise," and, as the opening quotation describes, was fairly sedate and alcohol-free (T. Walsh, personal communication, 2017). On the day I went, I was lucky: it was sunny and we moved through a busy city in a crowd of queer people, which felt "gently subversive" due to our being in public outside of the official Pride day (T. Walsh, personal communication, 2017). However, the demographic of the tour was mostly white, with a cismale presenting to mostly cis-male gays, with only a smattering of trans or non-binary people, and some women. Perhaps not surprisingly, most of the content of the tours centred white cis-male enabled gay experiences. This led me to question Walsh's use of 'queer' in his walking tour title, especially as I found out later that different incarnations of the tour focused on the 'gay' aspect or left references to sexuality out altogether. ${ }^{\text {iii }}$

When I later interviewed Walsh, he explained that he used 'queer' as his preferred umbrella term for the LGBTQ+ community, which some might criticise as a form of erasure for 
not referencing those who face other forms of oppression, such as people of colour, people with disabilities, and trans people (Springgay \& Truman, 2019; Cohen, 1997). Nonetheless, Walsh's umbrella understanding of queer comes from his experience as an Irish historian, archivist, and activist. By framing the tour in this way, Walsh actively plays on how queer can refer to a category of identity (Miller, Taylor \& Rupp, 2016); it has the potential to welcome LGBTQ+ people to engage with a shared, queer collective history, such as myself (Wyker, 2016). Walsh's title also alludes to the way in which his stories contribute to an 'anarchive' - something that is invented but is never complete ${ }^{\text {iv }}$ - that extends the processual queering of place started with the IQA to unsettle heteronormative histories in Ireland (Truman \& Springgay, 2019; Madden, 2013).

\section{Ireland's Heteronormativity}

Queering Dublin through heritage walks must be situated within the context of a larger heteronormative Irish colonial history, which shaped how LGBTQ+ people became marginalised in society after Britain banned homosexuality in the nineteenth century. ${ }^{\mathrm{v}}$ The 'body politic' of the new Republic of Ireland was strongly influenced by the Catholic Church and its religious values and moralities, which strictly disciplined bodies, and gendered and sexed identities (Dunphy, 1997; Han \& O’Mahoney, 2014). Indeed, homosexuality was only decriminalised in 1993 after a long civil rights campaign, even though LGBTQ+ events were organised in Dublin following the Stonewall Uprising in the United States in the early 1970s. Beginning with picnics, events soon became more radical, and in 1974 ten people marched to protest the ongoing criminalisation of homosexuality, leading to Ireland's first large-scale Pride march in 1983. This was to highlight violence against LGBTQ+ people after the attack and murder of a gay man named Declan Flynn in Dublin, and to protest the light sentences given to the perpetrators (Walsh, 2015).

In 2015, the national Marriage Equality Act and Gender Recognition Act passed in Ireland, and two years later the first openly gay Taoiseach (Irish Prime Minister) was elected. These changes have certainly advanced the worldwide opinion of Ireland as being a more equal, tolerant society, but evidence suggests that a culture of acceptance has not yet been created. For example, given the Catholic Church's continued control of primary and secondary education, queer history and culture is generally not included in education settings, and sex education remains very limited (Kearns and Meredith, 2014). ${ }^{\text {vi }}$ The Vatican's freshly issued document about gender, which rejects trans bodies or any notion of gender fluidity, ${ }^{\text {vii }}$ is reflected in Ireland by the cancellation of a recent Drag storytelling event in a Dublin library after the Dún Laoghaire-Rathdown County Council bowed under public pressure that connected the event to 'child abuse' (Gilmartin, 2019). Moreover, studies reveal that people underestimate the levels of homophobia, biphobia, and transphobia in Ireland, with ' 1 out of 5 LGBTQ+ people saying they have been physically attacked in public for being LGBTQ+' (Dunne, 2019). Events and research such as these indicate there is still much to be done around de-stigmatising LGBTQ+ people here (Rodgers, 2018).

Alluding to this marginalisation, Walsh hints towards the political roots of the walking tour; "the fact of the matter is you can't deny that historically so much of our history was destroyed or ignored-it was wilfully ignored" (T. Walsh, personal communication, 2017). In redressing this paucity of information, Walsh articulated the intent of the walking tour as "reminding us first of all of unfinished business, but also gearing us up to fighting the fight and redoubling our efforts to consolidate our stories" (T. Walsh, personal communication, 2017). ${ }^{\text {viii }}$ As a historically activist member of the gay community, Walsh's walking tour and related stories are not redundant simply because they prioritise white male cis-gender gay 
stories and memories: in the context described above, the tour encourages a wider discourse about queer memory while also challenging the heteronormative discourses still present in postcolonial Ireland today.

\section{The Walking Tour as Activist Public Pedagogy: Queering the City}

Walsh's walk to significant places, be they materially and/or digitally present, is a form of relational public pedagogy that contributes towards a queer discourse of Ireland. Broadly defined as learning at "sites of education" (Sandlin, Burdick \& O’Malley, 2011, p. 338) outside of recognised educational settings, the Queer History Walking Tour animates places for participants through the personal stories of the guides, and through embodied learning of places in the everyday fabric of the city. Below I examine the walking tour as a unique method for activist and political education, highlighting how knowledge and meaning are created and mobilised through embodied and storied visits to the places where that knowledge is produced (McKibben, 2014). The tour is a 'knowledge-practice' deployed within an activist framework; it facilitates the diffusion of information to the public by visiting places of ongoing struggle for equality, in this case Dublin, and appending stories to them (Casas-Cortés, Osterweil \& Powell, 2008). As an activist public pedagogy, I understand the walking tour as involved in an iterative, creative process of queering the city that contributes to the "ongoing composition of traces," including memories, that make up place (Anderson, 2015, p.14).

The Queer History Walking Tour through Dublin invites participants to voice their queer experiences and memories "grounded in a very distinct personal reality," offering stories about significant historical events for the larger gay community (T. Walsh, personal communication, 2017). As previously mentioned, Walsh's personal reality invokes a wellknown pattern of enabled white cis-male homonormativity still evident at Pride events and throughout LGBTQ+ history in general (Madden, 2013; Connolly \& O'Toole, 2005). Nonetheless, framed by Walsh's intention to queer Irish history, the tour becomes an anarchive 'supplement' to the IQA that diffuses stories for others to build upon ("Anarchive Concise Definition," n.d.). Moreover, Walsh has developed the walk and responded to this critique though inviting new tour guides such as Dr Mary McAuliffe. As a feminist and a queer woman, McAuliffe offers a wider focus on the tour by telling stories about historical lesbian women, but also stories about trans people and gay men. As a consequence, there was a more diverse demographic in the audience for these tours, which made the space feel more inclusive.

This inclusivity was facilitated by walking together, which is an innately social and interactive process (Lee \& Ingold, 2006). Throughout the tour people were free to move amongst the group and connect with or assist one another. As an interactive, mobile activity the tour provided a space for the group dynamic to become less hierarchical with attendees invited to contribute their stories to the queered discourse of Dublin. People shared umbrellas and spoke to each another, along with asking questions as we went from one stop to the next. By being welcoming and open, the walk provoked intergroup dialogue and brought people within the queer community together to share their knowledge and discuss their experiences. Historical stories were told such as those of lesbian individuals who lived with their partners their whole lives and fought in the Irish Citizen Army, but are rarely identified and recognised in the overarching masculinist narrative of the Easter Rising, which many consider a turning point in the Irish struggle for independence from Britain. ${ }^{\mathrm{ix}}$ Sharing stories with other queer people contributes to the way queer people learn about the world, with the walking tour 
creating space to build connections specifically around queer cultural heritage (see Bell, 2010; Rappaport, 2000; Felski, 2000).

The walking tours are significant for creating a broad understanding of LGBTQ+ community advancement and organising in queer Irish socio-cultural and political history. As an intergenerational activity, older activists attending relayed some of their knowledge and understanding of some of the events discussed, such as the early stages of Pride in Ireland. Indeed, one of the attendees at McAuliffe's tour mentioned being attracted to the tour because of this focus; as someone who had recently 'come out,' they wanted to learn about LGBTQ+ community heritage in Ireland, as it had been denied to them throughout their Catholic upbringing. The notion of a shared queer heritage speaks to the intention of the tour to promote histories that are "wilfully ignored" (T. Walsh, personal communication, 2017). In this way, the tour facilitates us to make sense of our own experience of being queer in Ireland. By emplacing stories and queer cultural heritage, intergenerational connections are made which contribute to the 'feed-forward mechanism' ("Anarchive - Concise Definition," n.d.), driving the anarchive to generate new creative engagements through renewed traces inscribed onto places.

\section{Concluding Notes: Towards a Future of Queer Walking in Ireland}

Ongoing reflection among LGBTQ+ people in Ireland positions queer voices in conversation and tension with one another, and gives rise to possible new queer horizons. As Walsh's homonormative tour gave McAuliffe something to build upon, critiques of mainstream Pride have also produced more political events in their wake. Recently, tensions have arisen in Dublin around the corporatisation of Pride (Browne, 2007); queer and trans people are increasingly associated with movements against capitalist assimilation, signalling a new direction for queer walking in Ireland that goes beyond the burgeoning diversity of the Queer History Walking Tour. In this way, a final function of the tour is solidarity building; by sharing diverse queer stories it is "capable of building new political communities" through its connections to other movements (Giroux, 2016, p.1). The start of McAuliffe's walking tour this year included a call to move beyond what she called "just assimilating our stories and identities into the current status quo," and to participate in and support the anti-capitalist LGBTQ+ events now organised as part of more radical responses to Pride and within Irish LGBTQ+ activism more broadly.

Last year, in 2018, for example, the first Trans Pride March ended in north Dublin (outside of the mainstream Pride march route), where Declan Flynn's body was found in Fairview Park to highlight the ongoing violence done to LGBTQ+ people, particularly trans people. ${ }^{\mathrm{x}}$ Many LGBTQ+ people remember that the repercussions for his attackers were too lenient and have connected this to other events when the Gardai (police) and justice system have been insufficient in protecting LGBTQ+ people. Following this, Alternative Pride was organised by Queer Action Ireland (QAI) this year to criticise Pride's links to companies and institutions that enact systematic violence against queer people such as the Gardai by allowing them to walk in the Pride Parade. Furthermore, the Trans Pride event (2019) was held on the $27^{\text {th }}$ anniversary of Marsha P. Johnson's death, 'continuing the fight for Trans liberation and showing that we will not be silenced any longer' (Trans Pride Dublin, 2019). These examples indicate how places are continuously (re)made through walks; as people walk to specific historical places and tell stories about them, they inscribe new meaning onto the urban landscape, but also connect struggles across different time-spaces (Jurkiewicz, 2016, p.11; Rose, 1993). 
The variety of speakers at Trans Pride also signalled an intersectional understanding of LGTBQ+ experiences, and they were translated by an Irish Sign Language (ISL) interpreter. A call was put out for chairs so that people with disabilities could attend the rallies and listen to the speeches, stories, and songs. ${ }^{\mathrm{xi}}$ People from marginalised groups were invited to talk about their experiences, including Sara Phillips who spoke for the Transgender Equality Network Ireland (TENI), but has also recently established the Irish Trans Archive. An intersex person spoke about their growing organisation, and a trans person from the Travelling Community alluded to the racism that still exists in Ireland. Moreover, Delroy Mpofu from the Movement of Asylum Seekers in Ireland (MASI) commented on LGBTQ+ experiences of Direct Provision, the Irish system of holding asylum seekers while their applications are being considered, $^{\text {xii }}$ and the death of Ms Sylva Tukula, a trans woman who was mis-gendered during this process and suffered more so because of it. ${ }^{\text {xiii }}$ These speakers' stories spatialised Ireland as queer, connecting different movements across the nation through their broad list of demands to improve LGBTQ+ experiences such as: trans healthcare, ending violence against LGBTQ+ people, including Direct Provision, and more social housing. ${ }^{\text {xiv }}$

I have suggested in this article that the Queer History Walking Tour of Dublin operates as an activist public pedagogy that seeks to remember and communicate a sense of queer cultural heritage in Ireland. The tour is an "educational intervention" (Biesta, 2012, p. 684) that provides a test of human togetherness around who is included in the LGBTQ+ narrative in Dublin, particularly at Pride events. While the walking tour works at retaining and growing traditional community relations and queer historical knowledge through stories, Trans Pride looks to the future by making demands and protesting the current situation LGBTQ+ people find themselves in. Events such as Trans Pride and Alternative Pride offer not only an anti-capitalist critique of Pride but, by being organised in a widely inclusive manner, they push beyond what was once a more singularly led Queer History Walking Tour. Walking together to significant places, telling stories, and educating one another about the intersectional oppressions that LGBTQ+ people suffer is at once relational, pedagogical, and political. The events discussed here not only queer the current narrative of Pride, they also grow the queer community nationwide by challenging normativities and capitalism, revealing a trajectory that invites us to imagine and participate in walking towards an intersectional future of being queer in Ireland.

\section{References}

Anarchive - Concise Definition. (n.d.). Retrieved July 18 from SenseLab website: https://senselab.ca/wp2/immediations/anarchiving/anarchive-concise-definition/

Anderson, J. (2015). Understanding cultural geography: Places and traces. London, UK: Routledge.

Bell, L. A. (2010). Storytelling for social justice: Connecting narrative and arts in antiracist teaching. New York, NY: Taylor \& Francis.

Biesta, G. (2012). Becoming public: Public pedagogy, citizenship and the public sphere. Social \& Cultural Geography, 13(7), 683-697. https://doi.org/10.1080/14649365.2012.723736

Browne, K. (2007). A party with politics? (re)making LGBTQ Pride spaces in Dublin and 
Brighton. Social \& Cultural Geography, 8(1), 63-87. https://doi.org/10.1080/14649360701251817

Casas-Cortés, M.I., Osterweil, M. \& Powell, D.E. (2008). Blurring boundaries: Recognizing knowledge-practices in the study of social movements, Anthropological Quarterly, 81(1), 17-58.

Cohen, C. (1997). Punks, bulldaggers, and welfare queens, GLQ: A Journal of Lesbian and Gay Studies, 3(4), 437-465.

Connolly, L., \& O'Toole, T. (2005). Documenting Irish feminisms: The second wave. Dublin, IR: Woodfield.

Dunphy, R. (1997). Sexual identities, national identities: The politics of gay law reform in the Republic of Ireland. Contemporary Politics, 3(3), 247-265.

Dunne, P. (2019). Call it out campaign launched to battle homophobia, biphobia and transphobia in Ireland. Gay Community News. Retrieved May 20 from https:/gcn.ie/call-campaign-launched-homophobia/

Felski, R. (2000). Being reasonable, telling stories. Feminist Theory, 1(2), 225-229.

Gilmartin, C. (2019). Glitter Hole’s 'Drag StoryTime’ children's event cancelled at Dublin

Library. GCN. Retrieved April 15 from: https://gcn.ie/glitter-holes-drag-story-timecancelled/

Giroux, H. (2016). Public pedagogy and manufactured identities in the age of the selfie culture. Oxford Research Encyclopedia of Communication. Retrieved from http://oxfordre.com/communication/view/10.1093/acrefore/9780190228613.001.000 1/acrefore-9780190228613-e-112

Han, E. \& O'Mahoney, J. (2014). British colonialism and the criminalization of homosexu ality. Cambridge Review of International Affairs, 27(2), 268-288.

Jurkiewicz, S. (2016) Cultural activism through spatial practices: Walking tours and urban gardening in Kuwait City. ZMO Working Papers, No.14, 1-12

Kearns, G. and Meredith, D. (2014). Spatial justice, religion and primary education. In

G. Kearns, D. Meredith and J. Morrissey (Eds.), Spatial Justice and the Irish Crisis. Royal Irish Academy.

Lee, J., \& Ingold, T. (2006). Fieldwork on foot: Perceiving, routing, socializing. In P. Collins, \& S. Coleman (Eds.), Locating the Field. Space, Place and Context in Anthropology (pp. 67-86). Oxford, UK: Berg.

Madden, E. (2013). Queering Ireland, in the archives. Irish University Review, 43(1), 184221.

McKibben, S.E. (2014). Learning solidarity: Activist pedagogies and transnational knowledge production in Cuban and Iranian diasporic democracy movements. Retrieved from ProQuest Dissertations.

Miller, S., Taylor, V. and Rupp, L. (2016). Social movements and the construction of queer identity. In J. Stets \& R. Serpe (Eds.), New Directions in Identity Theory and Research, Oxford Scholarship Online. 
Mullally, U. (2018). I am Tonie Walsh: 'Godfather of Gay' brings LGBT history to life. The Irish Times. Retrieved November 26 from https://www.irishtimes.com/

Rappaport, J. (2000). Community narratives: Tales of terror and joy. American Journal of Community Psychology 28(1): 1-24. https://doi.org/10.1023/A:1005161528817

Rodgers, G. (2018). Being gay in Ireland: Resisting stigma in the evolving present. Lanham, MD: Lexington Books.

Rose, G. (1993). Feminism \& geography: The limits of geographical knowledge. Cambridge, UK: Polity Press.

Sandlin, J. A., O'Malley, M. P., \& Burdick, J. (2011). Mapping the complexity of public pedagogy scholarship: 1894-2010. Review of Educational Research, 81(3), 338-375. https://doi.org/10.3102\%2F0034654311413395

Trans Pride Dublin. (2019) Press Notice. Retrieved July 3 from https://www.facebook.com/events/363107677836527/permalink/471211963692764/

Springgay, S. \& Truman, S. E. (2019). Queering temporalities, activating QTBIPOC subjectivities and world-makings: Walking research-creation. MAI: FEMINISM \& VISUAL CULTURE. Retrieved from https://maifeminism.com/walking-researchcreation-qtbipoc-temporalities-and-world-makings/

Truman, S. E. \& Springgay, S. (2019). Queer walking tours and the affective contours of place. Cultural Geographies. Advance online publication. https://doi.org/10.1177/1474474019842888

Walsh, E. (2015, May 16). 10 milestones in Irish gay rights. The Irish Times. Retrieved from https://www.irishtimes.com

Wyker, C. B. (2016). Queering collective memory: Public history and the future of the queer past. Retrieved from ProQuest Dissertations. (10148304) 
Georgina Perryman is a PhD Candidate and recipient of the Faculty of Social Sciences John and Pat Hume PhD Fellowship in the Department of Geography at Maynooth University, Ireland. With a background in Equality Studies, she is involved with various social justice groups and critical walking pedagogy in higher education.

\footnotetext{
i Approximate figures from T. Walsh, personal communication, 2017

ii 'Blow-in' is a colloquial term in Ireland for someone who has recently moved from the 'outside' to an area where their family does not have a long-standing history.

iii St Patrick's Festival 2019 had a tour entitled 'Lavender Walk: Tour of Historic Gay Dublin', and another 'An Untold Story'.

iv I understand an anarchive as not simply an artefact for posterity but rather involved in creation and recreation as it's drawn on and added to; it moves other events to occur in its wake. In this way, it is conceived of as a 'seed bank for the dissemination of forces of emergent taking form' ("Anarchiving” n.d. Retrieved July 18 from SenseLab: http://senselab.ca/wp2/immediations/anarchiving/

$\checkmark$ The 1861 Offences Against the Person Act, and the 1885 Criminal Law (Amendment) Act.

vi 90 percent of students in primary education are enrolled in to schools with a Catholic ethos. Read here for more: https://www.irishtimes.com/news/education/a-snapshot-of-primary-education-in-2017-1.3007434

vii Read more here https://www.irishtimes.com/news/social-affairs/religion-and-beliefs/vatican-rejects-idea-peoplecan-choose-or-change-genders-1.3921015

viii As a living archive held in the National Library of Ireland, the IQA still accepts donations and deposits: https://gcn.ie/listing/irish-queer-archive/.

ix Read more about the revolutionary women here: https://dublininquirer.com/2015/11/25/it-s-time-to-acknowledge-thelesbians-who-fought-in-the-easter-rising-with-podcast

${ }^{\mathrm{x}}$ A gay man who was killed in 1983, instigating the first wide scale Pride protest event in Ireland.

xi Therese Cahill, a female 'limp-up' comic, performed some of her songs.

xii This is somewhat similar to a detention centre where asylum seekers await court dates and a decision on whether they will be accepted as refugees in Ireland. These are often inhumane conditions, despite the millions of euro that flood the hotels where people are held. See Vukašin Nedeljković’s work that uses photography to capture the conditions people are forced to live in here: http://www.asylumarchive.com/

xiii Read the full post from MASI here: https://www.facebook.com/321969801334321/posts/1158532517678041/

${ }^{x i v}$ Full list of demands on the event page here: https://www.facebook.com/events/363107677836527/
} 